\title{
Compulsory health and safety in a free society
}

\author{
B J Boughton Birmingham University
}

\section{Author's abstract}

The ageing population and new technology are both increasing the cost of our free health service, and there are sound economic reasons for extending measures which reduce the diseases common to our society. But if education fails to change public attitudes towards habits such as tobacco smoking and poor diet, to what extent is the State justified in compelling us to be healthy? This issue touches on the sensitive areas of personal freedom and responsibility and involves complex cultural, historical and economic considerations. Both governments and individuals can be criticised for the way this issue has been handled in the past, and it is hoped that the examples discussed in this paper will stimulate further debate.

George Bernard Shaw once said that one should use up one's health before one was too old to enjoy it. But we realise now, that many health problems in later life are the result of habits started in our youth, and the notion that youthful pleasures in particular maybe harmful to our well-being is now widely accepted. Recent economic difficulties, our ageing population and the escalating cost of high-technology medicine has led to a new impetus in preventive health care; furthermore it is suggested that new measures should be imposed by laws and that those who abuse them should be penalised. Individual freedom, we are reminded, has to be balanced against the limited funds available for health care and the government's utilitarian duty to maximise the use of these resources. Our society having already travelled some distance in this direction, I believe it is now important to assess the position of free societies on the issue of compulsory health and safety.

To begin, it is generally acknowledged that our individual actions should not endanger others and where necessary this principle should be enforced by law. It seems self-evident that certain disabilities are undesirable in occupations where this would endanger the general public. Airline pilots may not continue

\section{Key words}

Vehicle seat belts; Health and Safety at Work Act; tobacco diseases; water fluoridation; national diet; vaccination; sports injuries; private health insurance; free health service. flying if they develop poor vision, angina or epilepsy, and similar restrictions apply to locomotive or lorry drivers and also to some extent, to private motorists. There are customs regulations to prevent the importation of rabies and Lassa fever into our country and to limit the spread of diseases which are already endemic here. As a third example, violent psychopaths are detained in institutions, and we debar those with serious psychiatric problems from responsible occupations in the armed forces, police or civil service.

Whilst these are examples where it seems justifiable for the law to intervene, there are other situations in which such intervention is more difficult to justify. This is particularly so with laws which set out to limit the risks to which individuals expose themselves, laws which many would say demand an unacceptable loss of personal liberty. J S Mill wrote that the only purpose for which power can be rightfully exercised over any member of a civilised society against his or her will is to prevent harm to others. But the modern situation is more complex than this since our government shoulders not only the major responsibility for health care, but an additional duty to use public money wisely. Preventive health makes good economic sense, and if individuals wilfully endanger their health, it may be unreasonable for the State to pay for the consequences. But how should the State best tackle the problem of self-inflicted illness? It can monitor health hazards, and inform the public of the risks; but if education fails to influence attitudes, how far is compulsion justified? If a particular risk were both scientifically established and economically significant, many would support legislation, particularly if genuine attempts at education had failed. But if a risk involved pleasurable activities or religious convictions, one would hope that the State would tread carefully, particularly since the cost of policing unpopular new laws could outweigh any potential saving in health care. But we live in a country where our individual freedom is not protected by a formal constitution and most of us would not want to see the type of sterile paternalism which characterises some totalitarian societies. Even, however, if modern health care has become too expensive for our present economic resources, most people would still not wish to abandon the fundamental objectives of a free health service. It is 
with these considerations in mind that one could look for lessons we could learn from specific examples of compulsory health and safety legislation.

First there are the new road safety laws which compel us to wear motorcycle helmets and motor vehicle seat-belts. Road safety education such as the 'clunk-click' campaign, had not influenced public attitudes towards seat belts, and before the 1983 legislation only 40 per cent of drivers wore them. Since then, however, it is estimated that 95 per cent of motorists obey the new law, as a result of which it is estimated that 700 deaths and 6000 serious injuries have been avoided in a single year. This is an impressive achievement, and the Royal Automobile Club and others who objected to the principle of compulsion have since admitted to a change of heart. Resentment was felt more keenly by motorcycle enthusiasts, and some have ridden their machines, bare-headed through city centres, in defiance of the law. A few were arrested for aggressive provocation of the police but in general they aroused little public sympathy. A more sensitive aspect of the motorcycle helmet law was that it overruled the religious convictions of our Sikh community. This example serves to illustrate the resentment with which some adults react to this type of compulsion, and the undesirable effects of simplistic legislation in a society of innumerable minority interests. It can hardly be said that seat-belts and crash helmets detract from the pleasures of motoring and motorcycling respectively, and both this factor and the demonstrable reduction in the number of injuries has resulted in wide public tolerance of the new laws and the suppression of opposing minority interests.

The obvious comparison with diseases caused by tobacco or alcohol reveals a quite different story, however. Each year tobacco diseases add about $£ 155 \mathrm{~m}$ to the cost of the National Health Service (NHS) and no other single measure would more improve the nation's health than an effective reduction in tobacco smoking. Tobacco shortens lives through bronchitis, heart disease and cancer, and for every male killed in a road traffic accident forty men die because they smoke. With alcohol, in addition to its role in liver disease, peptic ulcers and neurological disorders, there is the additional damaging effect of alcoholism on social relationships. Epidemiologists have long pressed for prohibitive measures on tobacco smoking along the lines taken with marijuana, but there are formidable problems with this approach. First, we are told by the Tobacco Advisory Council that $\mathbf{9 0}$ per cent of British people wish to decide for themselves whether they smoke or not. Smoking therefore, whilst being increasingly recognised as harmful and antisocial, is still regarded as a pleasurable activity, and for this reason governments have been reluctant to proceed too quickly or to adopt prohibitive legislation. In the United Kingdom recent educational campaigns have brought about a 20 per cent reduction in cigarette smoking and in Norway there has been a successful ban on tobacco advertising and sports sponsorship. This most commendable and those still in favour of prohibition would do well to remember that the American prohibition of alcohol in the 1920 s generatege an uncontrollable wave of crime, and was eventually. abandoned having achieved none of its objectives. Prohibition of tobacco would deprive governments of their taxation and newspapers of their advertising revenue, in addition to creating unemployment in bo the brewing and the tobacco industries. The government profit from tobacco is not wideby appreciated and is the major reason for ambivalence towards the problem of tobacco-related disease. The taxation revenue from tobacco amounts to $£ 4450 \overrightarrow{\mathrm{m}}$ annually, a source second only to VAT and North Sea Oil. In addition there is a calculated saving of $£ 1500$ 畗 each year on pensions unclaimed because of prematufe deaths from tobacco disease. In contrast is the $£ 155 \overrightarrow{\mathrm{p}}$ annual cost to the National Health Service of treating tobacco diseases, and the mere $£ 3 \mathrm{~m}$ spent by the Health Education Council. Thus, whilst prohibition of marijuana is acceptable in this country, the same historical, cultural and economic factors do not apply to tobacco and alcohol. In addition, we must no overlook the fact that powerful as it is, epidemiology a blunt tool and millions of people smoke and drin without getting lung cancer or cirrhosis of the liver. We must also remember that those who inflict these diseases upon themselves have already paid additiong taxes on the tobacco and alcohol they have consunato Indeed, some would say that the present governm duties are already excessive, and have the undesirab effect of selectively removing the individual freedom of choice from the poorest members of society. For these reasons, it would not only be puritanical but also high counter-productive to attempt to ban alcohol and tobacco. This example also highlights the unfairness of taxation as a mechanism for controlling health risk and the ambivalence of governments towards health risks which constitute an enormous source of State income. Most people would probably therefore, opt for adequately funded educational pressure and a ban advertising and sports sponsorship as the preferrege approach to this problem.

Another example of legal intervention in this area the Government's Health and Safety at Work Act. This was originally created to reduce dangerous wo practices, but the law requires monitoring by $a \bar{b}$ extensive new government bureaucracy, and its cos? effectiveness remains most uncertain. In the buildin industry for instance, there are still thousands serious casualties each year but in the case of healid workers, millions of pounds have been speat preventing a mere handful of cases of hepatitis eac్ year. With an intelligent workforce, whose membes had their own self interest at heart, it is likely in the latter case that simple education schemes would have worked just as effectively and cost much less. As it i⿱ the law has been abused by health professions an supply industries alike to upgrade facilities, on the 
pretence that they are demanded by law. An aspect of this legislation not often appreciated is that the codes of practice apply both to employers and employees, and that workers may be disciplined or even sacked for failure to co-operate. In this example therefore, we see that such legislation may be costly, ineffective and misused. If our workplace is to become an arena for the expansion of compulsory health and safety, the enormous expense, for instance of protecting North Sea Oil workers must be considered. In addition it must be realised that the 7000 fatal home accidents each year far exceed the deaths on our roads. The Government is already considering far stricter control of domestic appliances, and it is not inconceivable that a whole range of further compulsory measures could be enforced upon the privacy of our own homes.

A further example concerns the fluoridation of water supplies. The present scientific evidence supports artificial fluoridation as an effective protection against dental caries, and claims to have established that fluoride's harmful effects are both minor and easily avoided. The task of implementing artificial fluoridation has fallen upon regional health authorities, since governments have consistently avoided becoming involved. Thus, if majority opinion were to be the basis for settling such matters, then the democratic processes leading to the implementation of artificial fluoridation leave much to be desired. Over the years, minority groups such as the Pure Water Association have sought legal injunctions to resist fluoridation and a recent major judgement against the Strathclyde Health Authority could now lead to a cessation of artificial fluoridation throughout the United Kingdom. The problems surrounding this example are not easily resolved. It is said for instance, that the scientific evidence assumes without justification, a complete understanding of the benefits and risks. The plaintiff in the Strathclyde case believed fluoride would poison her pure water supply and no matter how strong the case against her, the nature of scientific deduction does not permit us to disprove her viewpoint. Furthermore, the fluoridation of water denies individuals any opportunity to opt out, since water authorities supply large geographical areas and there is little opportunity to avoid their monopoly.

But without fluoridation, individuals may still opt for individualised treatment using cheap and effective methods. In addition, despite the significant national economic burden posed by dental caries, it can hardly be viewed as a serious risk to health. It can be asked with some justification therefore, whether individual freedom should be infringed for risks which might be considered negligible in ordinary life. Furthermore, those who concede the principle of artificial manipulation of water supplies would do well to consider how this could be applied to foodstuffs. There is a growing awareness of the relationship of diet to heart disease, strokes, cancer, and bowel disorders; and the growth of the health food industry has been helped by exhortations from the medical profession to eat more dietary fibre and less saturated fat. New dietary trends in the USA have resulted in a 25 per cent reduction in deaths from coronary artery disease. The recent report from the National Advisory Council on Nutrition Education (NACNE) advocates sweeping changes in the British national diet. There are, however, immense commercial and cultural obstacles to this programme and one is again left wondering whether compulsory measures may be contemplated. We already have statutory adjustments to the iron content of milled flour, and the prospect of manufacturing cheap, artificial foodstuffs provides ominous scope for legislative intervention. Those who are obese already pay higher life insurance premiums, and some would say they are guilty of self-neglect. But here the question of culpability is difficult or impossible to settle, since obesity may be viewed as the result of greed on the one hand, or misfortune on the other. In Japan some workforces have compulsory exercises each morning at their factories, and the growth of a keep-fit ethos in the West could lead to penalties for those who neglect to keep in shape. The example of fluoridation highlights therefore, the ultimate fallibility of scientific evidence, the injustice of monopolising the water supplies, the difficulty of legislating for relatively inconsequential health risks, and concessions which could lead to manipulation of foodstuffs and penalties for those who stray from the current ideal concept of a fit and healthy body.

But there is much that could be achieved by means of compulsion and there are always those who, motivated by the best of intentions, are keen on compulsory measures. Smallpox appears to have been eradicated by world-wide vaccination programmes whereas whooping cough re-emerged in the United Kingdom recently, following a decline in the nation's immunity to the bacteria. Parents may be reluctant to immunise their children when they see little of the disease, particularly if the vaccine might have side-effects such as permanent brain damage. But everyone benefits if immunisation is widespread and it can be argued that parents who fail to immunise their own children put other children at risk too. The compulsory lobby has also been active recently, calling yet again for a ban on boxing. They remind us that this is the only sport where the sole object is to injure one's opponent, and recent evidence from the British Medical Association (BMA) has shown that brain damage can be widespread, cumulative and irreversible. But if boxers are really made aware of the risks from the outset, and if children are not allowed to participate, it is difficult to justify banning an activity which brings pleasure to so many and which constitutes a risk to only small numbers of consenting adults. There have been further debates concerning the dangers of the rugby scrummage, calls to close the fells to walkers during bad weather, and questions asked about the cost and danger of air-sea rescue operations during the 1979 Fastnet Race. About $£ 7.6 \mathrm{~m}$ in third party insurance is claimed each year by the NHS from the private 
insurers of those responsible for road traffic accidents. The total cost to the NHS for road traffic injuries is about $£ 90 \mathrm{~m}$ per annum however, and Oxford Regional Health Authority has apparently been tempted to offload the entire expense of accidental injuries on to private insurance. Those who parachute for sport, rock-climb or motor-race could, according to this philosophy, find themselves without State health care in the event of accidental injury. This would be a major reversal of policy since in the past, we have always tried to encourage young people to overcome fear, and have successfully channelled man's inherent aggression for the benefit of society. But accidental injury in this context is no less self-inflicted than the smoker's lung cancer, and the example illustrates well the tension between individual freedom and personal responsibility in societies in which the State has taken over health care. The slippery slope of personal responsibility can take us still further if we think for a moment. Are those with hereditary diseases such as haemophilia, muscular dystrophy or sickle cell disease to be forced to accept compulsory sterilisation and abortion, or otherwise to bear the enormous additional cost of looking after the affected children themselves? Most people could not accept such a development and would say this removed any right we might have to call ourselves a caring society.

The political aspects of compulsory health and safety will continue to pose problems until health care is seen to be receiving a higher priority for national resources. In addition, the current budget of the Health Education Council is sadly inadequate, and governments will have to adopt a less hypocritical attitude towards health education, exemplified so blatantly with respect to tobacco advertising and the lack of government compensation for children brain damaged as a result of vaccination. Alternatives to health education are all subject to serious objections, and the time has come to debate what principles should apply to the decision-making process. A fair system which does not penalise the poorest members of society and which does not victimise people because of religion, race or inheritance must be the basis for this debate. In addition, the progressive loss of individual freedom of choice must be given much more consideration.

Compulsory health and safety is a very dangerous notion which may only be justifiable when the public health interest and not its economic interest is at stake. Sickness and death come to both the fit and the frail eventually, and few would admire the obsessive pursuit of fitness and health so humorously portrayed by Stephen Leacock in How to Live to be 200 (1). A health service based on personal culpability is neither a sound nor a Christian ideal, but the gradual erosion of individual freedom, by a State which finds itself increasingly unable to keep pace with the cost of modern medicine, is no less a grim prospect.

\section{Acknowledgements}

In the course of writing this article I have receive helpful advice from numerous colleagues and I would particularly like to acknowledge the useful discussions I have had with Professor E G Knox, Professor of Social Medicine; Professor D S Shovelton, Professor Conservative Dentistry and Professor B Isaace Professor of Geriatrics, University of Birmingham. would also like to thank Miss C Garvey for preparing the manuscripts.

\section{References}

(1) Leacock S. How to live to be 200. In: Literary lapseg London: John Lane, The Bodley Head, 1982: 42-48.

\section{Commentary}

R S Downie, Department of Moral Philosophy, Glasgo University.

I should like to comment on the concept ot compulsion as it occurs in Dr Boughton's interesting discussion. As he rightly says, compulsion requires justification aref the only consistent justification within the liberes tradition of J S Mill is that one's activities are harming others. Compulsion on the grounds that it is for o\& own good constitutes 'sterile paternalism', which Do Boughton regards as characteristic of totalitair societies.

But even within the liberal tradition the associâten ideas of 'harm to others' and 'compulsion' are?ngt without problems, empirical, procedural anfid conceptual. Take, for example, the case of tobacce. (Dr Boughton discusses the problems of alcohol at the same time, but since I think alcohol raises slight $\vec{B}$ different problems I shall confine myself for brevity tobacco). Dr Boughton points out that 'those w西 inflict lung cancer upon themselves have already paid additional taxes', and that 'it would not only puritanical but also highly counter-productive $\overparen{B}$ attempt to ban ... tobacco'. An empirical poigt complicating this concerns the way in which tobaccorelated diseases are transmitted. If it is true that your smoking can harm my lungs then, granted the many ways in daily life in which your smoke may enter my lungs, there is justification, if not for restricting you smoking as such, at least for greatly restricting the public places in which you are allowed to smoke Moreover, restrictions on smoking are 'puritanicăl' only to those who enjoy smoking. Leaving aside the question of health, we can still point out that increasing number of people dislike the smell of smoke, the way in which it clings to the clothes of the nopsmoker etc. Now, if it is an empirical fact that mang people dislike smoke, then the freedom and enjoyment of smokers in public places is at the expense of the freedom and enjoyment of the non-smoker, and it not therefore 'puritanical' to try to curb smokers.

But even granted that smoking might interfere wi the pleasure of non-smokers, and might even har 